\title{
Environmental Ecological Response to Increasing Water Temperature in the Daya Bay, Southern China in 1982-2012
}

\author{
Yanju Hao', Danling Tang2*, Laura Boicenco ${ }^{3}$, Sufen Wang ${ }^{2}$ \\ ${ }^{1}$ Yantai Research Institute, China Agricultural University, Yantai, China \\ ${ }^{2}$ Research Center for Remote Sensing of Marine Ecology \& Environment, State Key Laboratory of Tropical \\ Oceanography, South China Sea Institute of Oceanology, Chinese Academy of Sciences, Guangzhou, China \\ ${ }^{3}$ National Institute for Marine Research and Development "GrigoreAntipa", Constanta, Romania \\ Email: yanju_hao@126.com, "lingzistdl@126.com, sufenwang1976@126.com, laura_boicenco@yahoo.com
}

Received 5 January 2016; accepted 15 April 2016; published 18 April 2016

Copyright (C) 2016 by authors and Scientific Research Publishing Inc.

This work is licensed under the Creative Commons Attribution International License (CC BY).

http://creativecommons.org/licenses/by/4.0/

(c) (i) Dpen Access

\section{Abstract}

The increase of water temperature, due to thermal discharges from two nuclear power stations, was one of the most significant environmental changes since 1982 in the Daya Bay, located in the north of the South China Sea. This study investigates the long-term (1982-2012) environmental changes in Daya Bay in response to the increase of water temperature, via comprehensively interpreting and analyzing both satellite and in situ observations along with previous data. The results show that: 1) salinity, dissolved oxygen (DO), chemical oxygen demand (COD) and nutrients had been enhanced after the thermal discharges started in 1994;2) the concentration of Chl-a increased while the net-phytoplankton abundance decreased; 3) diversity of the phytoplankton community had decreased; 4) fishery production had declined; and 5) frequency of Harmful Algal Bloom occurrence had increased. Satellite images show clearly that a thermal plume from the power stations extended toward the interior of Daya Bay, and that surface temperature of the seawater increased as one approached the power stations. The analysis suggests that the thermal water discharged from the two power stations was a driver of the ecosystem's change in Daya Bay. Several factors, including nutrients, salinity, DO, and COD, varied according to the increase of water temperature. These factors affected the water quality, Chl-a, and phytoplankton in the short term and impaired aquatic organisms and the whole ecosystem in the long term.

\section{Keywords}

Daya Bay, Ecosystem, Thermal Discharge, Water Temperature, Nuclear Power Station

\footnotetext{
"Corresponding author.
} 


\section{Introduction}

Water temperature is one of the most important factors to marine ecosystems; small changes of water temperature could have considerable environmental impacts on ecosystems [1] [2]. Seawater warming can be caused by increasing mean global temperature or by local thermal discharge. Many studies show that serious ecosystem degradations are related to aggressive human activities, such as nutrient enrichment caused by increasing discharge of daily-life and industrial sewage, as well as toxins discharged from the cage culture [3]-[5]. Therefore, it is critical to study and understand the impact of water temperature changes on marine ecosystems, caused by, for example, thermal discharge or global warming.

Thermal discharge can cause undesirable changes of the environment [6]. Bays generally have amplified responses to environmental changes compared to open water bodies [7] [8]. Thermal pollution from power plants could elevate the seawater temperature and significantly impact the ecosystems of coastal bays [9]-[12]. We have been continuously observing water temperature in Daya Bay, where thermal water is being disposed from two nuclear power stations, for more than 10 years with particular attention to the ecological impacts of the thermal water in this region [13]-[16]. Phytoplankton and the primary productivity in the sea are an effective proxy of ecosystem changes, because of their sensitivity to variations in water temperature, salinity, abundance of nutrients, etc. As a result, the environmental impact on the ecosystem due to thermal water can be evaluated via analyzing the change in the amount, type, and distribution of the phytoplankton in the vicinity of the power stations in the bay. In addition, understanding the impact of human activity on the bay ecosystem has high significance to safe and sustainable exploits in the coastal water.

\section{Study Area}

The Daya Bay is a shallow semi-enclosed bay, with a southeastward opening, located in a subtropical region in the northern part of the South China Sea (SCS, Figure 1). It covers an area of $650 \mathrm{~km}^{2}$, its coastline is $52 \mathrm{~km}$, and its water depth is $10 \sim 20$ meters. The area of Daya Bay belongs to a typical subtropical marine climate, with an average annual rainfall of $1984.4 \mathrm{~mm}$ and an annual average relative humidity of $82 \%$. Its annual average temperature is $21.7^{\circ} \mathrm{C}$, while its extreme maximum temperature is $38.5^{\circ} \mathrm{C}$, and the extreme minimum temperature is $0.7^{\circ} \mathrm{C}$. Because of relatively fast wind speed, the area of Daya Bay has a frost-free period of 359.2 days per year. It experiences a strong northeast monsoon in winter and a weaker southwest monsoon in summer. During the winter, sea water mixes vertically due to the influence of the northeast monsoon, while in the summer the seawater with lower temperature and higher salinity from the southeast is injected into the bay, resulting in a stratified water column [17].

The Daya Bay experiences the development of industry, aquaculture, and agriculture in the nearby region since the 1980s. Change of landscape, partially in the bay, is revealed by comparing two remote sensing TM images from Landsat 5 (from 1991) and Landsat 8 (from 2013), respectively (Figure 1). It has been influenced by the rapid growth of coastal industries and human activities. Two nuclear power stations (Figure 1), the Daya Bay Nuclear Power Station (DNPS) and the Ling' ao Nuclear Power Station (LNPS), were built nearby the bay in 1994 and 2003, respectively (Table 1 \& Figure 1). The DNPS covers an area of about $10 \mathrm{~km}^{2}$, the annual power generation capacity is about 45 billion $\mathrm{KWH}$. Cooling water of $65^{\circ} \mathrm{C}$ from the DNPS is discharged into the bay at a rate of about $95 \mathrm{~m}^{3} \cdot \mathrm{s}^{-1}$, causing long term changes of the seawater interior for a. Studies show that thermal discharge poses an important effect on the ecosystems of the coastal seawater [13] [16] [18]. The thermal discharge provides an important opportunity for us to investigate how the marine ecosystem responds to increasing temperature in the coastal bay seawater.

The oceanography of Daya Bay had been studied via collecting ecological and environmental data before 1985, for the purpose of sitting and building the NPS. Multiple ecological and environmental factors have been monitored since 1982. The Marine Biological Research Station (MBRS), which is operated by the South China

Table 1. Locations of Daya Bay Nuclear Power Station (DNPS) and Ling’ao Nuclear Power Station (LNPS).

\begin{tabular}{ccccc}
\hline Name & Latitude & Longitude & Operation time & Generating capacity (per year) \\
\hline DNPS & $22^{\circ} 35^{\prime} 59.70^{\prime \prime} \mathrm{N}$ & $114^{\circ} 32^{\prime} 57.75 " \mathrm{E}$ & Feb., 1994 & 100 billion kilowatt-hours \\
LNPS & $22^{\circ} 36^{\prime} 02.70^{\prime \prime} \mathrm{N}$ & $114^{\circ} 33^{\prime} 0.75^{\prime \prime} \mathrm{E}$ & Sept., 2002 & 147 billion kilowatt-hours \\
\hline
\end{tabular}



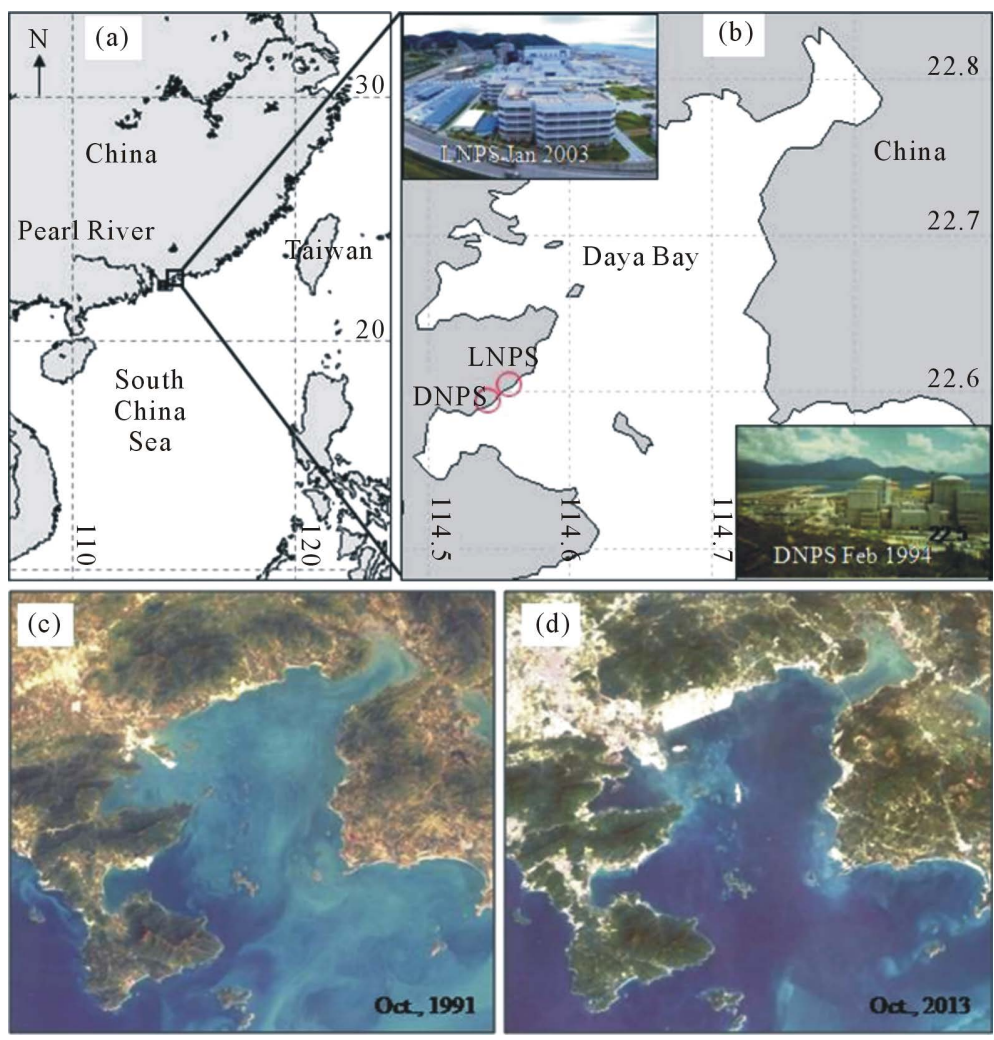

Figure 1. (a) The location of the Daya Bay; (b) Map of the Daya Bay with DNPS and LNPS (the circles) in the Dapeng Cove; (c) Remote sensing TM images for the Daya Bay in 1991 (Landsat 5); (d) Remote sensing TM images for the Daya Bay in 2013 (Landsat 8).

Sea Institute of Oceanology, Chinese Academy of Sciences, carried out four surveys per year in Daya Bay, including measurement of the physical-chemical parameters of the seawater as well as the composition and biomass of the biota at twelve stations in the bay. In this paper, we collect and analyze those ecological and environmental parameters, to address how the ecosystem can respond to thermal discharges from the two nuclear power stations.

\section{Increase of Water Temperature in the Daya Bay}

In the Daya Bay area, the annual mean air temperature is $22^{\circ} \mathrm{C}$, the coldest months are January and February, with a monthly mean of $15^{\circ} \mathrm{C}$, and the hottest months are July and August, with a monthly mean of $28^{\circ} \mathrm{C}$. The lowest sea surface temperatures are recorded in spring $\left(15^{\circ} \mathrm{C}\right)$ and highest ones in summer and fall $\left(30^{\circ} \mathrm{C}\right)$ [19].

From mid 1950s to mid 1990s, the mean global ocean-surface temperature has increased by $0.31^{\circ} \mathrm{C}$ due to the combined effects of natural variability and human activities [4] [20]. In Bohai Sea, northern China, a shallow semi-enclosed sea, the sea surface temperature increased at a rate of $0.011^{\circ} \mathrm{C} \mathrm{y}^{-1}$ from 1960 to 1997 [21]. In the Taiwan Strait, the SST increased by $1.0^{\circ} \mathrm{C}$ (at a rate of $0.045^{\circ} \mathrm{C} \mathrm{y}^{-1}$ ) from 1976 to 1998 , and the long-term net warming increased three-fold from the South China Sea to the East China Sea [22]. An early study on the Sea Surface Temperature (SST) in Daya Bay shows an increase rate of $0.11^{\circ} \mathrm{C} \mathrm{y}^{-1}$ during $1970-2005$ based on in situ data [15]. However, the increasing trend of the SST in Daya Bay from 1985 to 1993 indicates response of seawater in the bay to global warming, and the much faster increase rate for the period 1994 2005 might suggest the influence of thermal discharge from the NPS on the marine environment [15].

A comparative study of seawater temperature at twelve stations in Daya Bay before and after the start of operation of the DNPS found that, since the operation of the DNPS, the annual mean SST has increased by $0.34^{\circ} \mathrm{C}$, and the greatest recorded change was of $2.30^{\circ} \mathrm{C}$ in one summer [23]. Peng (2001) also showed that the seawater temperature in the bay increased by $0.77^{\circ} \mathrm{C}$ from 1993 to 1998 [24]. The spatial distribution of water tempera- 
tures showed high values in the western region of the Daya Bay, near the nuclear power stations, from 1996 to 2004, higher by about $1^{\circ} \mathrm{C}$ than in other areas; low values were found at the bay's mouth for all analyzed years [19].

With the development of space technology, more remote sensing data are currently available for monitoring and studying the marine environment [13] [25] [26]. Chen (2003) revealed the existence of thermal water anomaly near DNPS using the Landsat Thematic Mapper (TM) satellite remote sensing data for Daya Bay [27]. Satellite images show almost homogeneous distribution of SST in January 1985, whereas high temperature anomaly near the nuclear power stations in the western bay and relatively low temperature values at the opening in January 1999 (Figure 2). Tang (2003) employing for the first time AVHRR images in the study of thermal discharge from the DNPS, reported that the power station thermal discharge caused increasing water temperature, and the spatial distribution of thermal discharges had different seasonal patterns (Figure 2) [13]: the thermal plume extended over $40-100 \mathrm{~km}^{2}$ to the southeastern part of the bay in the summer, whereas it was limited to a rather small area in the western side of the power station, during the winter; This seasonal variation of the size of the thermal plume was attributed to the way the discharged water is mixing with the seawater. During the winter, the relatively warmer discharged water diffuses into the seawater quickly; therefore the area of thermal anomaly is small. In the summer, however, the disposed water is comparatively cooler and denser, resulting in a stratified flow on the surface of the seawater and much wider propagation.

Thus it can be seen that the combination of in situ data and satellite SST data provided a better understanding of the long-term environmental changes in Daya Bay in response to the variation of water temperature [14] [15] [18].

\section{Ecological Responds to Thermal Water Discharge from Power Stations}

\subsection{Environmental Changes}

Increased water temperatures may affect the water environment [2] [11]. Firstly, the spatial distributions and seasonal variations of Dissolved Oxygen (DO) are consistent with the water temperature. In light of the fact that the seawater complies with the First Class of National Seawater Quality Standards for China, this is probably due to the progressive increases of the SST, even though such cases were caused by the decline in water quality (eutrophication) in the past [3] [19].

The Chemical Oxygen Demand (COD) values were lower in Daya Bay than in the other seas in China, and showed two decreasing trend in 1989-1999, and 2001-2003, respectively, indicating that organic pollution was much lower in other seas in China [19].

The nutrient structure has been substantially changed since 1985 [14]. During the period of 1985-2004, the dissolved inorganic nitrogen increased from $1.53 \mu \mathrm{mol} \cdot \mathrm{L}^{-1}$ to $5.40 \mu \mathrm{mol} \cdot \mathrm{L}^{-1}$, while $\mathrm{PO}_{4}-\mathrm{P}$ and $\mathrm{SiO}_{3}-\mathrm{Si}$ decreased from $1.12 \mu \mathrm{mol} \cdot \mathrm{L}^{-1}$ and $39.50 \mu \mathrm{mol} \cdot \mathrm{L}^{-1}$ to $0.11 \mu \mathrm{mol} \cdot \mathrm{L}^{-1}$ and $12.82 \mu \mathrm{mol} \cdot \mathrm{L}^{-1}$, respectively. The average ratio of molar N/P showed an increasing trend from 1985 to 2004, although the molar Si/P decreased after 2002, its increasing trend was still obvious during 1985-2004 [16].

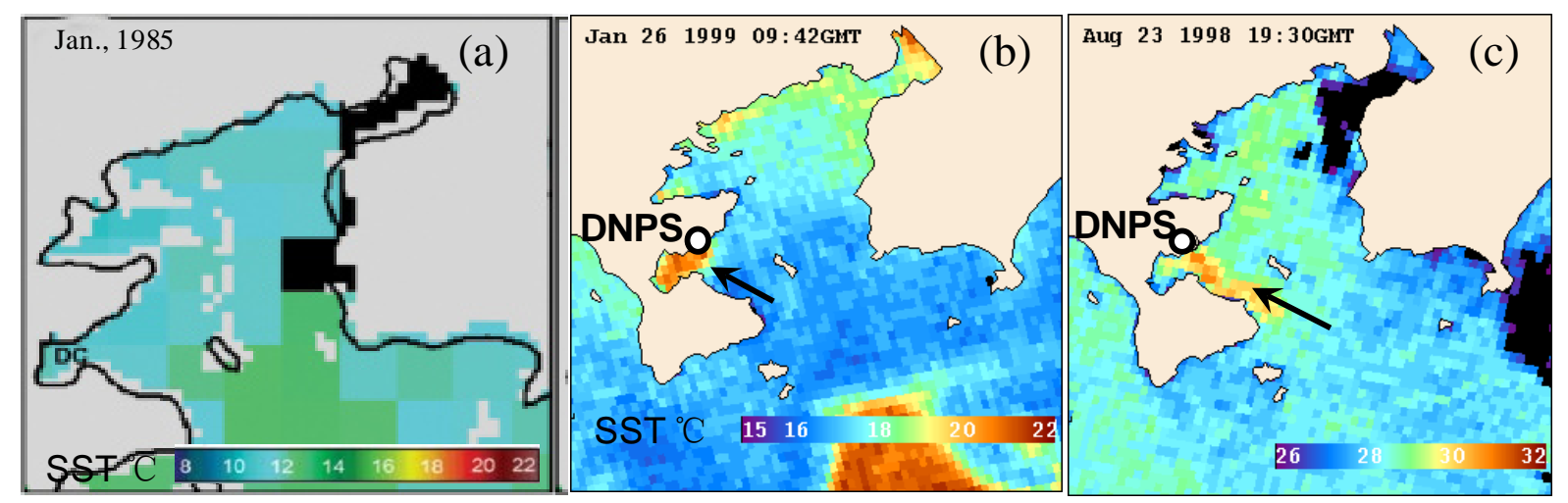

Figure 2. Satellite images showing SST in the Daya Bay before DNPS (a) and after DNPS (b), (c), and seasonal pattern of spatial distribution of thermal discharges. The circles indicate the location of the power station (DNPS); color bars with different ranges show sea surface temperature (SST). (a) January, 1985 [14]; (b) January, 1999 [13]; (c) August, 1998 [13]. 


\subsection{Changes of Phytoplankton Communities, Increases Chl-a and Harmful Algal Bloom (HAB)}

The Chl-a, biomass and phytoplankton community structure, caused by human activity, pollution and eutrophication, have been changed in recent years in Daya Bay [5] [28]-[30]. The thermal water discharge from nuclear power stations can lead to stronger stratification and changes in hydrodynamic condition, which may affect algal growth [13] [15] [18] [19]. Water temperature increase was the most important factor affecting the changes in concentrations and species composition of the phytoplankton community, which could decrease the biomass, density, and species composition [6] [31] [32]. In Daya Bay, after 1994, the amount of warm-water phytoplankton species and the relative percentage of dinoflagellate increased, while the net-phytoplankton decreased coincidently with the increase of Chl-a concentrations [33]-[35].

Water temperature is usually low in winter months (November to February) in Daya Bay, but it increased after 1994, making the water conditions more favorable to algal growth [31] [32] [36]. Although the mean annual abundances of phytoplankton showed a decreasing trend, the phytoplankton cell density in end-autumn and winter days has increased comparatively [36]. However, compared to the increasing trend of Chl-a, the annual mean net-phytoplankton abundances and phytoplankton species were lower in the years after 1994 than the period from 1985 to 1993 . The changes in phytoplankton communities might indirectly influence the middle sections of the food chain in the bay such as fish, the number of species, and individual weight of the fish, for example [19].

The decreased net-phytoplankton abundance and increased Chl-a indicate that, responding to the increased water temperature, the diversity of phytoplankton community has decreased, and the phytoplankton communities tend to be dominated by small-sized species [16]. As a result, the percentage of relative big-cell species, such as Rhizosolenia alata f. gracillima, Chaetoceros compressus, C. pseudocurvisetus, R. alata, C. curvisetus, C. siamense, and Bacteriastrum hyalinum, dominating the cell density of the entire phytoplankton community, decreased from 1982 to 1998, while the percentage of relative small-cell species, such as Nitzschia pungens, Skeletonema costatum, C. affinis, and Leptocylindrus danicus increased during the same period (Figure 3).

In the South China Sea, occurrences of HABs are closely related to water temperature, especially in the waters adjacent to Daya Bay [37] [38]. Relevant studies showed that when approaching the power station, the water

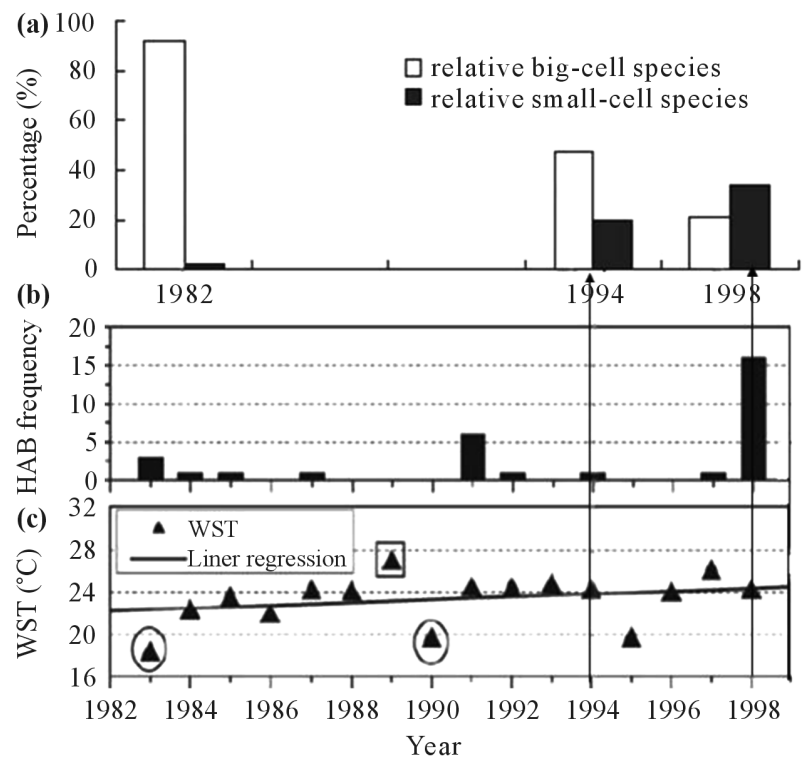

Figure 3. Phytoplankton community cell size and occurrences of HABs in the Daya Bay associated with water temperature from 1982 to 2004. (a) The decrease of the percentage of relative big-cell species of phytoplankton community and the increase of relative small-cell species during 19821998 [16]; (b) Occurring frequencies of HABs; (c) Water surface temperature [15]. 
temperature increases and could create conditions favorable for algal growth [6] [36]. In Daya Bay, as the water temperature increased, the occurrence frequencies of HABs also significantly increased after 1994 (Figure 3). In the HAB events, new warm-water algal species such as Peridinium quinquecorne was observed while water temperature was relatively warm, the duration of HAB has become longer, and the HAB-affected area has extended [14] [15] [18].

The Chl-a concentration increased from 1985 to 2004, and the annual Chl-a concentrations were all higher during 1994-2004 than in the years before 1994 [19]. Tang et al. observed the Chl-a concentration in the whole bay and found the concentration was coincident with variations of water temperature [13]. High Chl-a concentration was found near the DNPS [14] [18], suggesting the high Chl-a concentration resulted from the warm water discharge. In addition to the effect of water temperature, the growth of phytoplankton is limited by nitrogen in spring and winter, and by phosphate in summer and autumn, therefore high values of TIN/P and Si/P occurring in recent years has caused the increasing and higher values of Chl-a concentration in summer and autumn [19].

\subsection{Other Marine Organisms Response to Water Temperature Increase}

In Daya Bay, NPP have a proven impact on the ecological environment, and water temperature is one of the major influencing factors [13]-[15] [18]. The influences of increasing water temperature can be demonstrated by the increase of Chl-a concentration and the decrease of phytoplankton abundances. The activities of organisms in subsequence trophic levels such as the spawn, growth, prey of fish, shrimp and shellfish in the bay are also critically impaired. Finally the fishery declined and became limited to a certain small community [39] [40]. Generally, both the main fish species and the mean individual fish weight decreased from 1985 to 2005 [19].

The present macrozoobenthic community in Daya Bay is different from that of the 1980s', with largely different species and reduced community stability and complexity [41]. Due to increasing water temperature, there was a significant decline in coral coverage during the past 25 years (i.e., 76.6\% coral coverage in 1983/1984 dropped to only $15.3 \%$ in 2008). The dominant species of coral community changed from Acropora pruinosa to Favites abdita [42]. As the hermatypic corals were demolished, the phenomenon of stony coral bleaching appeared [19]. These results indicate that warm water from the DNPS and LNPS has great ecological effects.

\section{Summary}

Long-term variation of water temperature has clear correlation with ecological parameters. Taking 1985 as a reference, there were obviously larger average variations of the ecological parameters during 1997-2004 compared with the period of 1987-1991 (Table 2). That suggests that the increasing water temperature amplified the variations and the effects of other factors. Previous statistical analysis also showed that the change of phytoplankton community cell size structure was more due to water temperature than nutrients [16], suggesting that

Table 2. The average variational range of the ecological parameters in the periods of 1987-1991, 1994, and 1997-2004, taking reference of 1985.

\begin{tabular}{cccc}
\hline Average variational range of parameters & $1987-1991$ & 1994 & $1997-2004$ \\
\hline $\mathrm{T}\left({ }^{\circ} \mathrm{C}\right)$ & -0.63 & 0.58 & 0.67 \\
Chl-a $\left(\mathrm{mg} / \mathrm{m}^{3}\right)$ & 0.32 & 0.63 & 1.14 \\
Cells density $\left(\times 10^{7} \mathrm{ind} / \mathrm{m}^{3}\right)$ & -4.41 & & -5.98 \\
Species & 8 & -47 & -51 \\
Total inorganic nitrogen $(\mu \mathrm{mol} / \mathrm{L})$ & 0.6 & 0.34 & 3.01 \\
$\mathrm{SiO}_{3}-\mathrm{Si}(\mu \mathrm{mol} / \mathrm{L})$ & -18.84 & -26.05 & -21.09 \\
$\mathrm{PO}_{4}-\mathrm{P}(\mu \mathrm{mol} / \mathrm{L})$ & -0.762 & -0.86 & -0.99 \\
$\mathrm{Molar} \mathrm{TIN} / \mathrm{P}$ & 4.57 & 5.92 & 36.75 \\
$\mathrm{Molar} \mathrm{Si} / \mathrm{P}$ & 22.44 & 17.15 & 119.76 \\
\hline
\end{tabular}




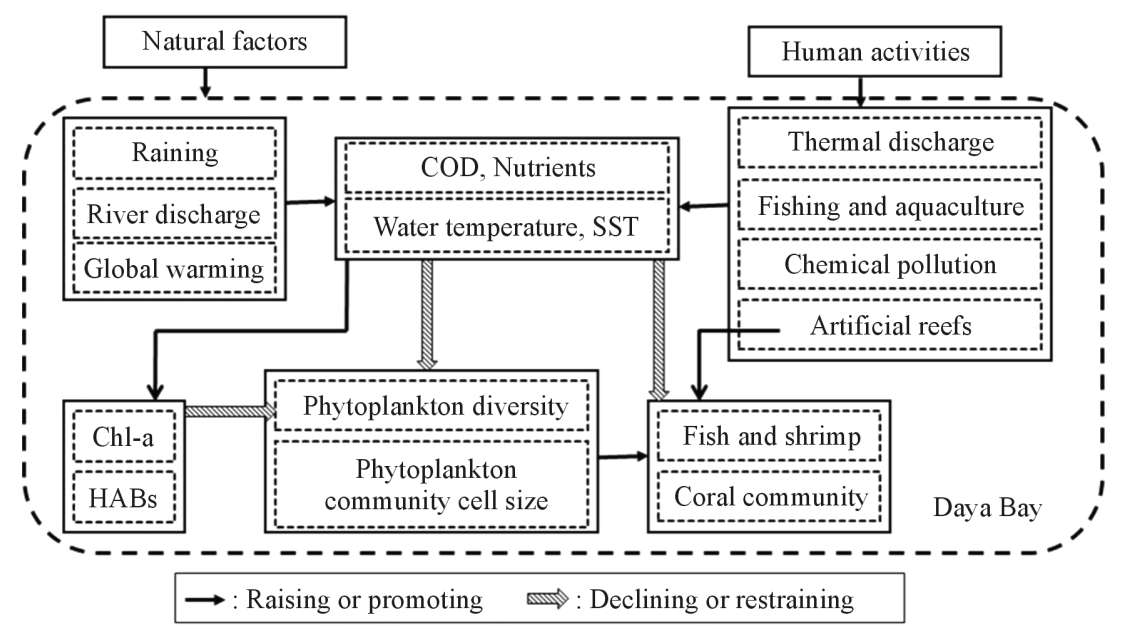

Figure 4. Concept of environmental factors that affect ecosystem of the Daya Bay.

variation of water temperature was more influential than nutrients on the organisms. As a result, warm water accelerated the growth of some phytoplankton, and caused increase of Chl-a, but the whole phytoplankton abundance and species diversity decreased. Phytoplankton species with relatively large body size were overwhelmed by species with relatively small body size; therefore the area was dominated by smaller species. The ecological environment tended to decline, coinciding with thermal discharge from the NPS.

In conclusion, Daya Bay has been affected by both natural factors (such as global warming) and human activities, where human activities, including coastal changes, pollution, and thermal discharge, have worse impacts (Figure 4). The increasing water temperature due to thermal discharges from two NPS is a major environmental driver that can enhance other impacts. Reduction of the negative influence of human activities is greatly suggested to protect the ecological environment of Daya Bay.

\section{Acknowledgements}

This study is supported by research projects awarded to Professor Dan Ling Tang: 1) Key project, National Natural Sciences Foundation of China (41430968). 2) The open project of State Key Laboratory of Tropical Oceanography, South China Sea Institute of Oceanology, Chinese Academy of Sciences (LTO1204). 3) China Petroleum \& Chemical Corporation (313099). 4) China-Romania Inter-Governmental S\&T Cooperation (41-26, Tang and Boicenco).

\section{References}

[1] Tang, D.L., Kawamura, H., Shi, P., Takahashi, W., Shimada, T., Sakaida, F. and Isoguchi, O. (2006) Seasonal Phytoplankton Blooms Associated with Monsoonal Influences and Coastal Environments in the Sea Areas Either Side of the Indochina Peninsula. Journal of Geophysical Research, 111, G01010. http://dx.doi.org/10.1029/2005JG000050

[2] Saravanan, P., Priya, A.M., Sundarakrishnan, B., Venugopalanb, V.P., Rao, T.S. and Jayachandran, S. (2008) Effects of Thermal Discharge from a Nuclear Power Plant on Culturable Bacteria at a Tropical Coastal Location in India. Journal of Thermal Biology, 33, 385-394. http://dx.doi.org/10.1016/j.jtherbio.2008.06.006

[3] Dale, B. (2009) Eutrophication Signals in the Sedimentary Record of Dinoflagellate Cysts in Coastal Waters. Journal of Sea Research, 61, 103-113. http://dx.doi.org/10.1016/j.seares.2008.06.007

[4] Nerem, R.S., Leuliette, E. and Cazenave, A. (2006) Present-Day Sea-Level Change: A Review. C. R. Geoscience, 338, 1077-1083. http://dx.doi.org/10.1016/j.crte.2006.09.001

[5] Song, X.Y., Huang, L.M., Zhang, J.L., Huang, H.H., Li, T. and Su, Q. (2009) Harmful Algal Blooms (HABs) in Daya Bay, China: An in Situ Study of Primary Production and Environmental Impacts. Marine Pollution Bulletin, 58, 13101318. http://dx.doi.org/10.1016/j.marpolbul.2009.04.030

[6] Briand, F.J.P. (1975) Effects of Power-Plant Cooling Systems on Marine Phytoplankton. Marine Biology, 33, $135-148$. http://dx.doi.org/10.1007/BF00390718

[7] Mustard, J.F., Carney, M.A. and Sen, A. (1999) The Use of Satellite Data to Quantify Thermal Effluent Impacts. Estu- 
arine, Coastal and Shelf Science, 49, 509-524. http://dx.doi.org/10.1006/ecss.1999.0517

[8] Fox, M.F., Kester, D.R., Andrews, J.E., Magnuson, A. and Zoski, C.G. (2000) Seasonal Warming of Narragansett Bay and Rhode Island Sound in 1997: Advanced Very High Resolution Radiometer Sea Surface Temperature and in Situ Measurements. Journal of Geophysical Research, 105, 22071-22082. http://dx.doi.org/10.1029/1999JC000146

[9] Horvath, R.S. and Bren, M.M. (1972) Thermal Pollution and the Aquatic Microbial Community: Possible Consequences. Environmental Pollution, 3, 143-146. http://dx.doi.org/10.1016/0013-9327(72)90034-1

[10] O’Riley, S.C., Fausch, K.D. and Guwan, C. (1992) Movement of Brook Trout (Salvelinus fontinalis) in Four Small Subalpine Streams in Northern Colorado. Ecology of Freshwater Fish, 1, 112-122. http://dx.doi.org/10.1111/j.1600-0633.1992.tb00080.X

[11] Ahn, Y.H., Shanmugam, P., Lee, J.H. and Kang, Y.Q. (2006) Application of Satellite Infrared Data for Mapping of Thermal Plume Contamination in Coastal Ecosystem of Korea. Marine Environmental Research, 61, 186-201. http://dx.doi.org/10.1016/j.marenvres.2005.09.001

[12] Teixeira, T.P., Neves, L.M. and Araújo, F.G. (2009) Effects of a Nuclear Power Plant Thermal Discharge on Habitat Complexity and Fish Community Structure in Ilha Grande Bay, Brazil. Marine Environmental Research, 68, 188-195. http://dx.doi.org/10.1016/j.marenvres.2009.06.004

[13] Tang, D.L., Kester, D.R., Wang, Z.D., Lian, J.S. and Kawamura, H. (2003) AVHRR Satellite Remote Sensing and Shipboard Measurements of the Thermal Plume from the Daya Bay, Nuclear Power Station, China. Remote Sensing of Environment, 84, 506-515. http://dx.doi.org/10.1016/S0034-4257(02)00149-9

[14] Yu, J., Tang, D.L., Oh, I.S. and Yao, L.J. (2007) Response of Harmful Algal Blooms to Environmental Changes in Daya Bay, China. Terrestrial, Atmospheric and Oceanic Sciences, 18, 1011-1027. http://dx.doi.org/10.3319/TAO.2007.18.5.1011(Oc)

[15] Yu, J., Tang, D.L., Yao, L.J., Chen, P.M., Jia, X.P. and Li, C.H. (2010) Long-Term Water Temperature Variations in Daya Bay, China Using Satellite and in Situ Observations. Terrestrial, Atmospheric and Oceanic Sciences, 21, 393-399. http://dx.doi.org/10.3319/TAO.2009.05.26.01(Oc)

[16] Hao, Y.J., Tang, D.L. and Boicenco, L. (2012) Variations of Phytoplankton Community Structure in Response to Increasing Water Temperature in the Daya Bay, China. Journal of Environmental Protection and Ecology, 13, 17211729.

[17] Tang, D.L. and Ni, I.H. (1996) Remote Sensing of Hong Kong Waters: Spatial and Temporal Changes of Sea Surface Temperature. Acta Oceanographic Taiwanica, 35, 173-186.

[18] Yu, J., Tang, D.L., Wang, S.F., Lian, J.S. and Wang, Y.S. (2007) Changes of Water Temperature and Harmful Algal Bloom in Daya Bay in the Northern South China Sea. Marine Science Bulletin, 9, 26-33.

[19] Wang, Y.S., Lou, Z.P., Sun, C.C. and Sun, S. (2008) Ecological Environment Changes in Daya Bay, China, from 1982 to 2004. Marine Pollution Bulletin, 56, 1871-1879. http://dx.doi.org/10.1016/j.marpolbul.2008.07.017

[20] Levitus, S., Antonov, J.I., Boyer, T.P. and Stephens, C. (2000) Warming of the World Ocean. Science, 287, $2225-2229$. http://dx.doi.org/10.1126/science.287.5461.2225

[21] Lin, C., Su, J., Xu, B. and Tang, Q. (2001) Long-Term Variations of Temperature and Salinity of the Bohai Sea and Their Influence on Its Ecosystem. Progress in Oceanography, 49, 7-19. http://dx.doi.org/10.1016/S0079-6611(01)00013-1

[22] Belkin, M.I. and Lee, M.A. (2014) Long-Term Variability of Sea Surface Temperature in Taiwan Strait. Climatic Change, 124, 821-834. http://dx.doi.org/10.1007/s10584-014-1121-4

[23] Huang, X.N., Zhu, Z.H. and Xu, M.C. (1998) Variation of Water Temperature in the Southwestern Daya Bay before and after the Operation of Daya Bay Nuclear Power Plant. In: Pan, J.P. and Wang, Z.D., Eds., Annual Research Reports (II): Marine Biology Research Station at Daya Bay, Science Publishing House, Beijing, 102-112.

[24] Peng, Y.H., Chen, H.R., Pan, M.X., Huang, H.H. and Gao, H.L. (2001) The Primary Production and Potential Fishery Production in the Sea Area around the Daya Bay Nuclear Power Station before and after the Operation of DBNPS. Journal of Fisheries of China, 25, 161-165.

[25] Tang, D.L., Kester, D.R., Ni, I.H., Kawamura, H. and Hong, H. (2002) Upwelling in the Taiwan Strait during the Summer Monsoon Detected by Satellite and Shipboard Measurements. Remote Sensing of Environment, 83, 457-471. http://dx.doi.org/10.1016/S0034-4257(02)00062-7

[26] Wynne, T.T., Stumpf, R.P., Tomlinson, M.C., Ransibrahmanakul, V. and Villareal, T.A. (2005) Detecting Karenia brevis Blooms and Algal Resuspension in the Western Gulf of Mexico with Satellite Ocean Color Imagery. Harmful Algae, 4, 992-1003. http://dx.doi.org/10.1016/j.hal.2005.02.004

[27] Chen, C.Q., Shi, P. and Mao, Q.W. (2003) Application of Remote Sensing Techniques for Monitoring the Thermal Pollution of Cooling-Water Discharge from Nuclear Power Plant. Journal of Environmental Science and Health (Part 
A-Toxic/Hazardous Substance \& Environmental Engineering), 38, 1659-1668. http://dx.doi.org/10.1081/ESE-120021487

[28] Zhou, P., Lin, Y. and Wang, Z. (1998) A Statistical Analysis on Phytoplankton Community Features in Waters of Daya Bay. Tropic Oceanology, 17, 57-64.

[29] Zhou, J.L. and Maskaoui, K. (2003) Distribution of Polycyclic Aromatic Hydrocarbons in Water and Surface Sediments from Daya Bay, China. Environmental Pollution, 21, 269-281. http://dx.doi.org/10.1016/S0269-7491(02)00215-4

[30] Wu, M.L. and Wang, Y.S. (2007) Using Chemometrics to Evaluate Anthropogenic Effects in Daya Bay, China. Estuarine, Coastal and Shelf Science, 72, 732-742. http://dx.doi.org/10.1016/j.ecss.2006.11.032

[31] Wang, Z.H., Chen, J.F., Xu, N. and Qi, Y.Z. (2001) Relationship between Seasonal Variations in Gymnodinium spp. Population and Environmental Factors in Daya Bay, the South China Sea. Acta Ecologica Sinica, 21, 1825-1832.

[32] Song, X.Y., Huang, L.M., Zhang, J.L., Huang, X.P., Zhang, J.B., Yin, J.Q., Tan, Y.H. and Liu, S. (2004) Variation of Phytoplankton Biomass and Primary Production in Daya Bay during Spring and Summer. Marine Pollution Bulletin, 49, 1036-1044. http://dx.doi.org/10.1016/j.marpolbul.2004.07.008

[33] Sun, C.C., Wang, Y.S., Sun, S. and Zhang, F.Q. (2006) Dynamic Analysis of Phytoplankton Community Characteristics in Daya Bay, China. Acta Ecologica Sinica, 26, 3948-3958. http://dx.doi.org/10.1016/S1872-2032(07)60005-5

[34] Wang, Z.H., Qi, Y.Z., Chen, J.F., Xu, N. and Yang, Y.F. (2006) Phytoplankton Abundance, Community Structure and Nutrients in Cultural Area of Daya Bay, South China Sea. Journal of Marine Systems, 62, 85-94. http://dx.doi.org/10.1016/j.jmarsys.2006.04.008

[35] Wang, Z.H., Zhao, J.G., Zhang, Y.J. and Cao, Y. (2009) Phytoplankton Community Structure and Environmental Parameters in Aquaculture Areas of Daya Bay, South China Sea. Journal of Environmental Sciences, 21, 1268-1275. http://dx.doi.org/10.1016/S1001-0742(08)62414-6

[36] Liu, S., Huang, L.M., Huang, H., Lian, J.S., Long, A.M. and Li, T. (2006) Ecological Response of Phytoplankton to the Operation of Daya Bay Nuclear Power Station. Marine Environment Science, 25, 9-25.

[37] Tang, D.L., Kester, D.R., Ni, I.H., Qi, Y.Z. and Kawamura, H. (2003) In Situ and Satellite Observations of a Harmful Algal Bloom and Water Condition at the Pearl River Estuary in Late Autumn 1998. Harmful Alga, 2, 89-99. http://dx.doi.org/10.1016/S1568-9883(03)00021-0

[38] Tang, D.L, Di, B.P., Wei, G., Ni, I.H., Oh, I.S. and Wang, S.F. (2006) Spatial, Seasonal and Species Variations of Harmful Algal Blooms in the South Yellow Sea and East China Sea. Hydrobiologia, 568, 245-253. http://dx.doi.org/10.1007/s10750-006-0108-1

[39] Qiu, Y.W., Wang, Z.D. and Zhu, L.S. (2005) Variation Trend of Nutrient and Chlorophyll Contents and Their Effects on Ecological Environment in Daya Bay. Journal of Oceanography in Taiwan Strait, 24, 131-139.

[40] Sun, B.Q., Li, H.X. and Yan, Y. (2007) Fish Community Diversity in the Western Daya Bay Waters. Fisheries Science, 26, 394-399.

[41] Du, F.Y., Wang, X.H., Li, C.H., Zhang, H.H. and Jia, X.P. (2009) Macrobenthic Community Structure in Daya Bay, South China Sea. Acta Ecologica Sinica, 29, 1091-1098.

[42] Chen, T.R., Yu, K.F., Shi, Q., Li, S., Price, J.G., Wang, R., Zhao, M.X., Chen, T.G. and Zhao, J.X. (2009) Twenty-Five Years of Change in Scleractinian Coral Communities of Daya Bay (Northern South China Sea) and Its Response to the 2008 AD Extreme Cold Climate Event. Chinese Science Bulletin, 54, 2107-2117. http://dx.doi.org/10.1007/s11434-009-0007-8 